\title{
Investigating implementation issues for workload control (WLC): A comparative case study analysis
}

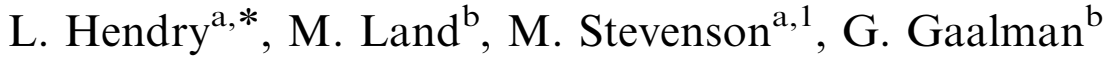 \\ ${ }^{a}$ Department of Management Science, Lancaster University Management School, Lancaster University, Lancaster LA1 $4 Y X$, UK \\ ${ }^{\mathrm{b}}$ Faculty of Management and Organisation, University of Groningen, P.O. Box 800, 9700 AV Groningen, The Netherlands
}

Received 30 January 2007; accepted 13 May 2007

Available online 5 July 2007

\begin{abstract}
Workload control (WLC) is a method of production planning and control, which when commenced at the customer enquiry stage, has particular relevance to producers of highly customised products. Although previous research has suggested that WLC has great potential to improve performance, only a few successful case studies have been reported. To facilitate more widespread use of WLC, this paper seeks to investigate issues that arise from implementing WLC systems through a rare comparative case study analysis. Two companies are studied, a capital goods manufacturer and a precision engineering sub-contractor. The study initially identifies emerging research questions that address 17 implementation issues, including those related to the market/customer, the primary manufacturing process, the WLC system requirements, the flow of information and embedding WLC within the organisation. For each implementation issue, an appropriate response is given that leads to changes in the theory underpinning WLC or the development of WLC implementation strategy. Finally, areas in need of further research are suggested, providing direction for fellow scholars in the field of WLC. These areas include the further refinement of the implementation requirements for WLC in additional case study settings and the need for simulation studies to verify the effectiveness of some of the proposed changes to the underlying theory of WLC.
\end{abstract}

(C) 2007 Elsevier B.V. All rights reserved.

Keywords: Workload control (WLC); Make-to-order (MTO) industry; Production planning and control (PPC); Implementation issues; Empirical research

\section{Introduction}

As customers become more demanding, the need for industry to provide more highly customised products continues to increase. Thus, the make-to-

\footnotetext{
*Corresponding author. Tel.: + 441524593841 ; fax: +441524844885 .

E-mail addresses: 1.hendry@lancaster.ac.uk (L. Hendry), m.j.land@rug.nl (M. Land), m.stevenson@lancaster.ac.uk (M. Stevenson), g.j.c.gaalman@bdk.rug.nl (G. Gaalman).

${ }^{1}$ Tel.: + 441524594015 ; fax: + 441524844885 .
}

order (MTO) sector of industry is of continued importance, and includes capital goods manufacturers as well as many small- and medium-sized enterprises (SMEs), providing customised goods as part of a supply chain. In a recent review of the production planning and control (PPC) literature by Stevenson et al. (2005), in which workload control (WLC) is described, it has been argued that WLC is the approach with the highest relevance to many MTO companies, given that it provides more of the required features than the other alternatives. For 
example, WLC explicitly addresses the customer enquiry stage at which many such firms are involved in competitive bidding, enabling both realistic and competitive bids to be determined. In addition, it has also been recently argued that WLC has the potential to enable MTO SMEs to be more effectively integrated into the supply chain (Hendry, 2006). Thus, research into WLC to date has concluded that it has the potential to significantly improve the operating performance of the MTO sector of industry.

The overwhelming majority of contemporary research in the field of WLC is simulation based: see, for example, Perona and Portioli (1998), Oosterman et al. (2000) and Henrich et al. (2006). Although some recent experiments have explored ways of replicating real-life job shops in a simulation environment (for example, Bertrand and Van Ooijen, 2002), it has been acknowledged that the job shops found in practice are much more complex than those used as the basis for most simulation models (see Perona and Miragliotta, 2000). Thus, to gain a more detailed understanding of the effect of WLC on performance in practice, case study evidence is needed. Despite this, empirical studies are comparatively few and far between, the most notable contribution in recent times being by Park et al. (1999). A consequence of the lack of empirical research is that little has been written about the process of implementation itself in a WLC context. This paper seeks to address this gap in the literature, thereby facilitating more widespread implementation of WLC.

It is noted that it is inevitable that some of the issues critical to the implementation of WLC are also important to the application of other companywide initiatives; however, it is not our aim to rediscover issues such as the need for careful change management, to have top-level management involvement and to ensure the project is championed. Instead, this paper seeks to build on this, adding new and much needed insights into implementation issues that are specific, or of particular importance, to WLC due to its characteristics, data requirements and so on. Such insights may consequently ease the implementation process or lead to changes (or simplifications) in the associated WLC methodology. The relevance of these insights can then be investigated in the context of other innovative PPC systems, such as POLCA (see Suri, 1999) and CONWIP (see Hopp and Spearman, 1996).

The remainder of the paper is organised as follows. A more thorough review of the relevant literature is given in Section 2, where this need to investigate implementation issues is further justified. Section 3 describes the research methodology undertaken, indicating that a comparative case study analysis has been used to first identify and explore the implementation issues that arose and then to consider how these issues can be addressed. It is noted that there are a number of different approaches to WLC, the particular approaches used in this study are therefore briefly described in Section 4. The main focus of the paper, the discussion of the implementation issues, is then presented in Sections 5 and 6, with the former presenting the case study evidence and the latter providing detailed discussion. Finally, in Section 7 , conclusions are drawn along with the identification of areas in need of further research.

\section{Literature review: insights into the WLC implementation process}

In contrast to WLC, there is a vast literature surrounding the implementation of other planning systems such as material requirements planning (MRP) and enterprise resource planning (ERP); for recent examples, see Sumner (2000), Motwani et al. (2002), Mandal and Gunasekaran (2003), Muscatello et al. (2003), Yusuf et al. (2004) and Dowlatshahi (2005). Despite this attention, the implementation of MRP is continually criticised for having a low implementation success rate (Hong and Kim, 2002; Petroni, 2002). Hence, implementation is a complex and important issue of strategic relevance to all PPC concepts and implementation projects. While the implementation of any information system is a diverse issue incorporating, for example, issues of organisational politics, cultural change and project management, this paper will focus on issues of specific importance to PPC, and in particular WLC. Hence, the remainder of this review concentrates on insights provided by researchers involved in previous WLC research, with most emphasis on empirical studies. Reviews of the many PPC concepts are provided by Gelders and Van Wassenhove (1981), Hendry and Kingsman (1989), Zäpfel and Missbauer (1993) and Stevenson et al. (2005). For issues of general relevance to the implementation of planning concepts, the reader is referred to Stadtler and Kilger (2002) and Vollmann et al. (2004).

Previous empirical WLC research can be classified into three groups, labelled (1)-(3) below. In 
addition, simulation studies that consider implementation issues provide a fourth category of previous papers to be included in this review. Hence, the four categories discussed here are

(1) empirical studies that focus on the variant of WLC being used and the results of the WLC implementation,

(2) empirical studies that give some insights into certain aspects of the implementation process,

(3) empirical studies that propose an implementation strategy for WLC and

(4) simulation studies that consider implementation issues.

Within the first category are papers by Bertrand and Wortmann (1981), Bechte (1988, 1994) and Park et al. (1999). These papers provide valuable and rare evidence of the positive effect of WLC on performance in practice. However, they all focus on the methodology of the WLC concept proposed and the results of the implementation. They do not give detailed insights into the process of implementation itself.

Within the second category of empirical studies, Hendry (1989) and Hendry et al. (1993) look at issues that arise during the implementation process and which can lead to the misuse of the WLC system, preventing it from being fully tested in practice. Both of these studies highlighted the need for the end-user to be appropriately trained so as to ensure that the planning system is used appropriately and does lead to changes in the work being released to the shop floor. Thus, these papers tend to focus on pitfalls to avoid rather than issues that arise and how to overcome these issues successfully.

Within the third category is the work of Fry and Smith (1987) and Wiendahl (1995). The former propose a six-stage implementation procedure, which applies to the job release stage of WLC, and does not encompass the customer enquiry stage. In contrast, the work of Wiendahl (1995) considers a more complex WLC approach and thus this work provides the most comprehensive implementation strategy discussed in the literature to date. It covers six stages, including an analysis of the current manufacturing performance, looks at how to change company attitudes and concludes with a full implementation of the proposed WLC system. However, this still does not generate a comprehensive list of the implementation issues that can arise and how they should be overcome. Furthermore, the six-stage strategy has been developed in the context of a particularly complex variant of the WLC approach (for a discussion of alternative approaches, see Stevenson and Hendry, 2006). In contrast, this paper considers two alternative approaches that may be easier to implement in practice, as discussed further in Section 4.

Within the fourth category, theoretical simulation-based WLC research has recently begun to advocate and explore the use of grouping machines as a means to improve the feasibility of implementing WLC in practice, with the most notable contribution from Henrich (2005) and Henrich et al. (2004). By grouping interchangeable machines, individual machine data can be collated within a work centre and reported back to the planning system at regular intervals, thus providing a realistic information feedback system. Grouping machines serves to simplify the WLC system and parameter setting process; for example, backlog limitations can be determined for a work centre rather than for each individual machine. An alternative use of simulation to improve practical implementation is presented by Wiendahl et al. (1995). The authors develop an interactive simulation-based user-training tool for WLC. This provides a dynamic environment used to improve awareness and user understanding of WLC and to aid parameter setting. For example, users of the simulation package can assess the impact of parameter setting on inventory levels and lead times while also exploring the time delays between changing parameters and the change having an impact on shop floor performance. Such an approach could be a very useful pre-implementation training tool which could potentially avoid the misuse of the system observed by Hendry (1989) and Hendry et al. (1993).

While a number of implementation issues have been discussed through simulation studies and previous empirical research, there have not been any previous attempts to focus primarily on the issue of implementing WLC or to produce a comprehensive list of implementation issues along with appropriate responses to address them. This paper addresses this gap by considering such issues in the context of two case study companies undergoing a WLC implementation. A number of the issues raised during the case study research have been addressed, thereby contributing to the development of WLC theory and a WLC implementation strategy; others are highlighted as important topics requiring future research. In addition, future 
research should seek to build on the implementation strategy of Wiendahl (1995) to ensure wider applicability across WLC concepts and types of company, though this is beyond the scope of this paper.

\section{Research methodology}

Two research questions addressed in this paper are as follows:

(1) "What are the implementation issues that arise in the context of WLC?"

(2) "How should the implementation issues that arise in the context of WLC be addressed to enable improved implementation in practice?"

It is noted that the second of these research question is very broad and thus more detailed research questions emerged as the research progressed, which are specific to the implementation issues that arose. These are introduced later in the paper, in Section 5.

As discussed in the previous section, there has been very little WLC research that attempts to comprehensively identify implementation issues in this context; hence, the research described herein is exploratory in nature. Much of the research in WLC to date has been deductive, building theoretical models and testing them using a theoretical simulation model. In this paper, the methodology employed is based more on an inductive approach, in which case study evidence is collected to enhance existing, and develop new, theory regarding both the WLC concept and the surrounding implementation process. Voss et al. (2002) explain that "the case method lends itself to early, exploratory investigations where the variables are still unknown and the phenomenon not at all understood" (see also Benbasat et al., 1987; Meredith, 1998). Two case study companies are investigated: in both cases, current software systems are being developed with the ultimate aim of implementing WLC in the companies in the long run; a partial implementation of WLC in one of the companies has been completed as is described by Stevenson (2006a). When exploring new (and building upon existing) theory, the multi-case method can be appropriate, augment external validity, guard against observer bias (Handfield and Melnyk, 1998; Meredith, 1998; Voss et al., 2002), aid triangulation and improve the generality of findings (Voss et al., 2002; Yin, 2003).
Every detail of implementation must be addressed in these studies, from determining planned shop floor capacities through to determining the needs of the end-user and finally feeding back information from the shop floor to close the loop. Thus, the manner of investigation should ensure that the required level of rich data is collected.

The selection of the case studies must be undertaken with care in order to generate meaningful results. Yin (2003) identifies the "typical" case as an example of a case study approach for which even the single case study can be appropriate. In this research, care has been taken to ensure that both the companies are typical in terms of the production environments for which WLC concepts have been developed, as discussed in the following sub-section. It is argued here that two typical cases can provide more insights than a single case. Thus a comparative study, using tables to perform cross-case analysis, is used to further facilitate the identification of generic implementation issues within a WLC context (particularly if they arise in both cases). When an issue arises, it will be necessary to carefully analyse the reason for the issue. For example, it may be (i) related to a common characteristic of its production environment, and hence is a source of a potentially more generic solution or (ii) merely an idiosyncratic company-specific issue and hence not of wider relevance. Before such an analysis can be carried out, it is necessary to first consider the characteristics of the two companies by looking at both their similarities and their differences. For a more in depth description of the value of case research and its contribution to exploring new phenomenon and developing more elaborate theory, see, for example, Eisenhardt $(1989,1991)$ and Stuart et al. (2002).

\subsection{The case study company characteristics}

As discussed in Section 1, most authors of WLC concepts would agree that it has primarily been developed for the MTO sector of industry, in which there is a high level of customisation and a relatively broad product range. However, within the MTO sector, there is a wide diversity of companies. Stevenson et al. (2005) investigate the applicability of PPC concepts to the MTO industry, identifying three key characteristics to determine the type of MTO environment:

- The shop floor configuration: Whether it is a general flow shop (defined as materials flowing in 
the same direction but allowing the use of a subset of resources, thus permitting some customisation); or a general job shop (defined as allowing a multi-directional routing, although with a dominant flow direction, allowing greater customisation).

- The level of repeat production: Whether the company is a Versatile Manufacturing Company (VMC - negotiating for each order separately); or a Repeat Business Customiser (RBC-negotiating for a series of orders in a single contract), as first defined in Amaro et al. (1999).

- The size of the company: Whether the company is an SME or a large manufacturing enterprise.

Hendry (2005) goes into a greater level of detail, giving categories for the type of MTO production by:

- Identifying the point at which the customer order is received and therefore sub-dividing into engineer-to-order (ETO), MTO and assembleto-order.

- Identifying the type of customisation offered at that point, according to Mintzberg (1988), i.e., either pure, tailored or standardised.

In addition, Tobin et al. (1988) categorise using the type of production, whether geared towards a product or a process:

- Capital goods industry versus the sub-contracting industry, which makes up an important component of the supply chain.

Using these dimensions, the characteristics of the two companies can be described, as shown in Table 1. From Table 1, it can be seen that in terms of the two categories introduced by Tobin et al. (1988), there is one company of each type, i.e., one sub-contractor and one capital goods producer. As a consequence, the sub-contractor, Company $\mathrm{X}$, has a greater range flexibility and mix than the capital goods producer, Company B. The type of shop configuration supports the degree of flexibility, with the general flow shop suited to the production of a family of similar products and the general job shop suited to the greater flexibility found in the precision engineering environment. As is typical for a capital goods producer in the MTO sector, the type of customisation is tailored for Company $\mathrm{B}$, with a basic design in place, but adapted for each customer order. The number of orders of a similar type is very small and hence Company B is categorised as a VMC company. ETO, with pure customisation, is more typically associated with the precision engineering environment of Company $\mathrm{X}$, in which the company offers its skills and can design the products according to the customer's specification. Both companies are in the SME range, though Company $\mathrm{X}$ is clearly smaller than Company $\mathrm{B}$. It is therefore concluded that the two companies selected are typical of the types of MTO environments that are found in industry and for which the WLC concept has been developed.

\section{The variants of WLC}

The basics of WLC have been described by a number of authors, such as Stevenson et al. (2005) and Bergamaschi et al. (1997). A number of reviews have been written which discuss alternative variants of the WLC approach, including Land and Gaalman (1996), Bergamaschi et al. (1997), Sabuncuoglu and Karapinar (1999) and Stevenson and Hendry

Table 1

The case study company characteristics

\begin{tabular}{lll}
\hline Characteristic & Company B & Company X \\
\hline Market & $\begin{array}{l}\text { Capital goods, mainly conveyor } \\
\text { belts for agricultural purposes }\end{array}$ & $\begin{array}{l}\text { Subcontractor, precision engineering, for the } \\
\text { aerospace, automotive and defence industries }\end{array}$ \\
Shop floor configuration & General flow shop & General job shop \\
Type of MTO & MTO (tailored customisation) & ETO (pure customisation) \\
Level of repeat production & VMC & VMC/RBC \\
Company size & SME & SME \\
Employees & 80 employees & 30 employees \\
Turnover & 12.5 million euros approximately & 2 million euros approximately \\
\hline
\end{tabular}


(2006). Two key methods have been used in the case studies presented in this paper: an "aggregate load" approach is being implemented in Company X, while an "adjusted aggregate load" method is being implemented in Company B. The two approaches are very similar, both covering the key components of a comprehensive WLC approach (i.e., catering for the full planning and control process) as follows:

- Customer enquiry stage: Planning and control begins as soon as a customer enquiry is received, so that decisions regarding due date (DD) promises can be based on information on the current shop workload and outstanding bids awaiting customer confirmation/rejection.

- Job entry stage: Once an order is confirmed, further planning and control can be carried out to ensure that the input/output balance is retained, if required. Thus, more definite capacity plans can be put in place at this stage.

- Job release stage: Once the materials arrive for a confirmed order, the order is entered into a "preshop pool" of orders. It is not automatically released onto the shop floor. Instead, job release decisions are made periodically in order to ensure that the amount of work released for critical work centres is kept to a manageable level, where the time period between releases can be 1 week, 1 day or less. Final release decisions are made by the user of the WLC system: support is provided by the software in the form of latest release dates and load calculations. At the point of job release, capacity adjustments are considered where necessary in an attempt to ensure that jobs are released in time to meet the DD promises.

- Simplified shop floor control: The detailed scheduling task is assumed to be carried out by the shop floor supervisor. This task is simplified given the reduced shop workload, which results from the control of job release.

Both approaches require parameters for the workload limits, methods to measure the current and planned workloads and so on. The difference between the aggregate and adjusted aggregate approaches lies in the method used to calculate the workload at upstream work centres, with the adjusted method being more appropriate to the shop layout of Company B. For further details of the two approaches utilised, see Stevenson (2006a, b) and Land (2004), respectively; for a comparison of the two approaches by simulation, see Oosterman et al. (2000).

\section{The investigation of implementation issues: case study evidence and emerging research questions}

Section 4 discussed four key components of WLC: the customer enquiry, job entry, job release and the simplified shop floor control stages. These components influenced the perspective of WLC that is used in this section to identify implementation issues related to this concept. Fig. 1 illustrates the five basic sources of implementation issues that arose. The first two, (a) market and customer characteristics and (b) the primary process to be controlled, show complexities that have not been considered in the design of the WLC concept previously. The third, (c) the WLC system itself, includes certain conceptual aspects, which appear not to have been adequately developed thus far. The fourth, (d) organisational embedding, includes new issues regarding the embedding of a WLC concept within an organization, which emerged at the implementation phase. Finally, (e) information flows, includes solutions affecting the WLC approach, which were required to enable information to flow, both into and out of the WLC system and control the shop.

In Tables 2-6, the implementation issues that arose in both case study companies are reviewed. Regarding each issue, a case-specific comment is provided and in the final column a related research question is specified. Each emerging research question is intended to identify a gap in the WLC literature and is linked to the broader research question given in Section 3 on how to address the implementation issues to improve WLC implementation in practice. It is noted that the case study research also provided supporting evidence for

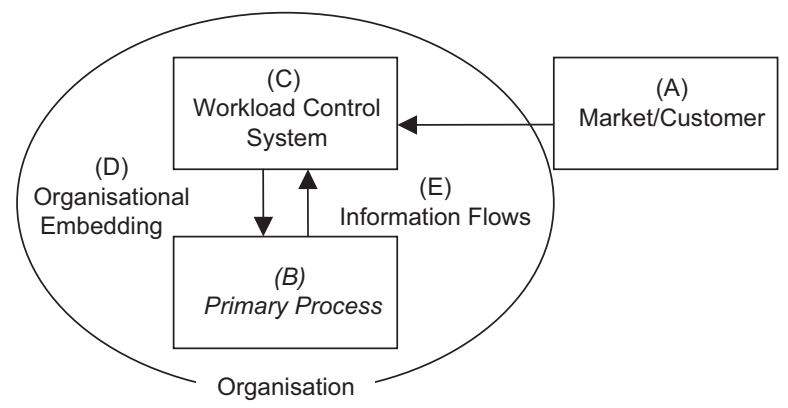

Fig. 1. Model applied to identify and classify issues related to WLC system implementation. 
Table 2

Case study evidence: the market/customer

\begin{tabular}{|c|c|c|c|}
\hline $\begin{array}{l}\text { Market/customer-related } \\
\text { issues (A) }\end{array}$ & Company B comments & Company X comments & Emerging research questions \\
\hline $\begin{array}{l}\text { A1: Characteristics of order } \\
\text { quotations }\end{array}$ & $\begin{array}{l}\text { Sometimes no clear due date is } \\
\text { specified. Instead, the agreement } \\
\text { is based on "delivery as soon as } \\
\text { possible" }\end{array}$ & $\begin{array}{l}\text { The typical job shop market } \\
\text { requires promising due dates } \\
\text { which are known to be } \\
\text { unrealistic: "tell the customer } \\
\text { what they want to hear" }\end{array}$ & $\begin{array}{l}\text { How can unrealistic and } \\
\text { unspecified due dates be handled } \\
\text { throughout the order process? }\end{array}$ \\
\hline $\begin{array}{l}\text { A2: Uncertainty at the } \\
\text { customer enquiry stage }\end{array}$ & $\begin{array}{l}\text { The time between a customer } \\
\text { enquiry and order confirmation } \\
\text { tends to be very short, i.e., this is } \\
\text { not a significant problem }\end{array}$ & $\begin{array}{l}\text { Customer confirmation lead } \\
\text { times are often unpredictable } \\
\text { (varying from the same day to } \\
\text { several weeks) and the probability } \\
\text { of "winning" the order is low }\end{array}$ & $\begin{array}{l}\text { How can uncertainty at the } \\
\text { customer enquiry stage be most } \\
\text { effectively incorporated in the } \\
\text { design of the WLC concept? }\end{array}$ \\
\hline A3: Rush orders & $\begin{array}{l}\text { The market segments show } \\
\text { extremely different due date } \\
\text { requirement characteristics. } \\
\text { Replacement orders for } \\
\text { machinery during the harvest } \\
\text { season require short due dates }\end{array}$ & $\begin{array}{l}\text { Priorities strongly differ among } \\
\text { customers, also related to } \\
\text { compensating past performances }\end{array}$ & $\begin{array}{l}\text { How can future, replacement } \\
\text { part, rush orders be considered } \\
\text { most effectively within the WLC } \\
\text { concept? }\end{array}$ \\
\hline $\begin{array}{l}\text { A4: Seasonality and volume } \\
\text { growth }\end{array}$ & $\begin{array}{l}\text { Demand follows strong seasonal } \\
\text { patterns resulting in periods of } \\
\text { under- and over-load }\end{array}$ & $\begin{array}{l}\text { The company is in a period of } \\
\text { growth and over-load }\end{array}$ & $\begin{array}{l}\text { How should demand patterns be } \\
\text { adopted in e.g., parameterisation } \\
\text { of the WLC concept? }\end{array}$ \\
\hline A5: Hybrid production & $\begin{array}{l}\text { In under-loaded periods, excess } \\
\text { capacity is filled with large stock- } \\
\text { replenishment orders for sister } \\
\text { companies }\end{array}$ & No stock items are present & $\begin{array}{l}\text { How can the release of stock } \\
\text { replenishment orders in periods } \\
\text { of under-load be fully } \\
\text { accommodated? }\end{array}$ \\
\hline
\end{tabular}

Table 3

Case study evidence: the primary process

\begin{tabular}{|c|c|c|c|}
\hline $\begin{array}{l}\text { Primary process-related } \\
\text { issues (B) }\end{array}$ & Company B comments & Company $\mathrm{X}$ comments & Emerging research questions \\
\hline B1: Assembly requirements & $\begin{array}{l}\text { There are two main parts to } \\
\text { conveyor belt production, } \\
\text { produced using two separate sets } \\
\text { of parallel processes, which are } \\
\text { then later assembled together }\end{array}$ & $\begin{array}{l}\text { Assembly is an issue only for a } \\
\text { limited number of products }\end{array}$ & $\begin{array}{l}\text { How should the workload } \\
\text { requirements of two separate } \\
\text { parts be treated when making a } \\
\text { release decision based on } \\
\text { workload norms? }\end{array}$ \\
\hline $\begin{array}{l}\text { B2: Sequence-dependent } \\
\text { set-up times }\end{array}$ & $\begin{array}{l}\text { Sequence-dependent set-up times } \\
\text { are recognised as an issue for } \\
\text { some heavily loaded machines }\end{array}$ & $\begin{array}{l}\text { Lot splitting decisions will affect } \\
\text { set-up times }\end{array}$ & $\begin{array}{l}\text { How can set-up sequences be } \\
\text { incorporated in WLC decisions } \\
\text { which normally assume constant } \\
\text { throughput times per operation? }\end{array}$ \\
\hline $\begin{array}{l}\text { B3: Alternative shop floor } \\
\text { routings }\end{array}$ & $\begin{array}{l}\text { Some machines are inter- } \\
\text { changeable, i.e., certain } \\
\text { operations can be performed on } \\
\text { several machines. Inter- } \\
\text { changeability is not "symmetric" }\end{array}$ & See Company B & $\begin{array}{l}\text { How can the grouping of } \\
\text { machines be organised such that } \\
\text { the full flexibility potential of } \\
\text { capacities is utilised? }\end{array}$ \\
\hline $\begin{array}{l}\text { B4: Industry-specific } \\
\text { processes, e.g., oven } \\
\text { processes }\end{array}$ & $\begin{array}{l}\text { It is expensive to "fire-up" the } \\
\text { oven. Batching occurs as a } \\
\text { consequence; orders have to wait } \\
\text { until sufficient load is available to } \\
\text { justify "firing-up" }\end{array}$ & $\begin{array}{l}\text { The company serves a variety of } \\
\text { customers and industries; hence, } \\
\text { industry-specific processes were } \\
\text { not noted. Batching is however a } \\
\text { problem with large quantity, } \\
\text { repeat orders }\end{array}$ & $\begin{array}{l}\text { How can the basic WLC } \\
\text { approach of creating regular } \\
\text { order arrival processes at } \\
\text { machines be adapted for } \\
\text { conflicting batching } \\
\text { requirements? }\end{array}$ \\
\hline
\end{tabular}


Table 4

Case study evidence: the workload control system

\begin{tabular}{|c|c|c|c|}
\hline $\begin{array}{l}\text { WLC system-related issues } \\
\text { (C) }\end{array}$ & Company B comments & Company X comments & Emerging research questions \\
\hline $\begin{array}{l}\mathrm{C} 1: \text { WLC-related start-up } \\
\text { issues }\end{array}$ & $\begin{array}{l}\text { In the current situation, } \\
\text { throughput times vary greatly } \\
\text { across operations }\end{array}$ & $\begin{array}{l}\text { Current lead times are longer } \\
\text { than would be competitive in the } \\
\text { long run }\end{array}$ & $\begin{array}{l}\text { How can the transition between } \\
\text { the actual situation and the } \\
\text { situation as ultimately enabled by } \\
\text { WLC be realised? To what extent } \\
\text { does the control imposed by } \\
\text { WLC enable the use of } \\
\text { standardised throughput times } \\
\text { across operations? }\end{array}$ \\
\hline
\end{tabular}

C2: Incomplete routing data before process planning has taken place

C3: Time-span-dependent critical resources
The sales department is able to determine a preliminary routing. The final routing is determined after process planning

Different capacity groups can be identified as potential bottlenecks in the release stage than in the acceptance stage where decisions are based on a longer planning horizon
Detailed routing data are not prepared until after an order is confirmed and the sales department does not produce a preliminary routing

No difference is noted between the decision levels; hence, this is not a significant issue to define in this company
How can acceptance and due date assignment decisions best be taken when there is incomplete routing data?

In what way can appropriate capacity groups be defined to reflect the critical or bottleneck resources at different decision levels?

Table 5

Case study evidence: organisational embedding

\begin{tabular}{|c|c|c|c|}
\hline $\begin{array}{l}\text { Organisational embedding- } \\
\text { related issues (D) }\end{array}$ & Company B comments & Company $\mathrm{X}$ comments & Emerging research questions \\
\hline $\begin{array}{l}\text { D1: Awareness of the } \\
\text { concept of WLC }\end{array}$ & $\begin{array}{l}\text { Planners have a tendency to } \\
\text { create precise plans at the shop } \\
\text { floor level, which may conflict } \\
\text { with assumptions of higher-level } \\
\text { WLC decisions }\end{array}$ & $\begin{array}{l}\text { Particular effort is required to } \\
\text { persuade employees against e.g., } \\
\text { the inclusion of a detailed discrete } \\
\text { scheduling module, which } \\
\text { conflicts with the more robust } \\
\text { WLC approach }\end{array}$ & $\begin{array}{l}\text { How can planners and other } \\
\text { personnel be trained such that } \\
\text { decisions will be taken in } \\
\text { correspondence with the } \\
\text { integrated WLC approach? }\end{array}$ \\
\hline D2: User visibility & $\begin{array}{l}\text { Despite the simple logic of the } \\
\text { WLC approach, calculations } \\
\text { appear to be rather complicated } \\
\text { for planners to understand. } \\
\text { Contrarily, users and not the } \\
\text { system should make the decisions }\end{array}$ & See Company B & $\begin{array}{l}\text { How can a good balance be } \\
\text { realised between showing (e.g., } \\
\text { graphically) only results of WLC } \\
\text { calculations, while maintaining } \\
\text { sufficient understanding of the } \\
\text { underlying logic for planners to } \\
\text { take the right measures? }\end{array}$ \\
\hline $\begin{array}{l}\text { D3: Support of task } \\
\text { structures }\end{array}$ & $\begin{array}{l}\text { Planning and sales tasks were } \\
\text { completely decoupled in the } \\
\text { current task structure, requiring } \\
\text { interaction for every due date } \\
\text { quotation }\end{array}$ & $\begin{array}{l}\text { No formal structure, sales and } \\
\text { planning often undertaken by the } \\
\text { same member of staff given small } \\
\text { size of organisation }\end{array}$ & $\begin{array}{l}\text { Which task structures can be } \\
\text { supported and and/or simplified } \\
\text { by the WLC concept and which } \\
\text { requirements are imposed by the } \\
\text { concept? }\end{array}$ \\
\hline
\end{tabular}

issues already identified in the literature. As the focus of this paper is on identifying new issues, these are not included in the tables unless they lead to changes in the state-of-the-art knowledge of WLC.

\section{Discussion of the case study evidence: addressing the research questions}

Having established a list of implementation issues in the previous section, this section discusses how 
Table 6

Case study evidence: information flows

\begin{tabular}{|c|c|c|c|}
\hline $\begin{array}{l}\text { Information flow-related } \\
\text { issues (E) }\end{array}$ & Company B comments & Company $\mathrm{X}$ comments & Emerging research questions \\
\hline $\begin{array}{l}\text { E1: System-related start-up } \\
\text { issues }\end{array}$ & $\begin{array}{l}\text { To prevent cumbersome } \\
\text { configuration of all orders in the } \\
\text { start-up portfolio, the system has } \\
\text { to run for at least a month only to } \\
\text { fill the database. The current } \\
\text { ERP system feeding the WLC } \\
\text { software will soon be replaced }\end{array}$ & $\begin{array}{l}\text { There is very limited data } \\
\text { available at the start of the } \\
\text { project, with no IT support for } \\
\text { planning }\end{array}$ & $\begin{array}{l}\text { How can the different levels of } \\
\text { IT-integration in SMEs be } \\
\text { supported in WLC? In which } \\
\text { ways can the start-up database } \\
\text { for a WLC system best be filled? }\end{array}$ \\
\hline $\begin{array}{l}\text { E2: Determining feedback } \\
\text { processes from, and data } \\
\text { provision to, the ERP } \\
\text { system }\end{array}$ & $\begin{array}{l}\text { Data structures in the ERP } \\
\text { system differ from the } \\
\text { requirements for planning } \\
\text { purposes } \\
\text { Uploading planning data in the } \\
\text { WLC system is impossible to } \\
\text { realise with the current ERP } \\
\text { system }\end{array}$ & $\begin{array}{l}\text { The company does not have an } \\
\text { ERP system, but similar } \\
\text { problems may arise with the } \\
\text { planned new information system }\end{array}$ & $\begin{array}{l}\text { How can WLC planning systems } \\
\text { be integrated with the ERP- } \\
\text { systems of the company? }\end{array}$ \\
\hline
\end{tabular}

the emerging research questions can be addressed by developing the underlying theory of WLC or developing elements of an associated WLC implementation strategy. Although methods of resolving most of the emerging questions are proposed here, it is noted that further research will be needed to explore their effectiveness in some cases, particularly where alternative approaches to an issue have been identified. Thus, issues that would benefit from further research beyond the scope of this paper are also identified in this discussion

\subsection{Market/customer-related issues (A1-A5)}

For the first issue (A1-characteristics of order quotations), the question of how to handle unrealistic or unspecified DDs can be addressed in two alternative ways. Of course, the question of when and why companies choose to offer unrealistic DDs is also an interesting issue to study and is an issue of broader relevance than WLC. However, this is beyond the scope of this paper and here we assume that for most companies, long-term competitiveness would be enhanced by offering more realistic DDs in general, as indicated by the case study evidence. Therefore, the first option is to consider this as something that requires a change of company culture to gain the confidence to quote realistically. This could be argued to be the most appropriate approach for Company $\mathrm{X}$, where the main issue is the quotation of unrealistic DDs. For Company X, field observations indicate that the desire of management to quote competitively, even if this means that bids are extremely unrealistic, leads to problems of deteriorating reputation among customers of the company. Therefore, it could be argued that this is a position that cannot be maintained in the long term. WLC can be an effective means of enabling realistic and competitive quotes to be given, but this requires a flexible approach, whereby capacity is changed (for example, through more flexible overtime patterns). In the long run, the use of WLC may lead to an increase in business confidence so that either more jobs are rejected or longer and more realistic lead times are quoted during periods of overload. Accepting this requires a change in mindset.

The second way to address issue (A1) is to use different DDs "in-house" to those quoted. This approach is argued to be more appropriate for Company B as the WLC concept enables a DD to be calculated that represents the earliest possible time, as is required by their customers when the DD is unspecified. Even for Company X, having two dates to use in the WLC system enables jobs to be tracked and lateness to be predicted, which may provide useful information to customers. In the revised WLC concept, it is possible to both look at predicted lateness and attempt to adjust capacity to deliver on time at each key decision stage, such as the job release stage.

The second issue (A2-uncertainty at the customer enquiry stage) highlights a contrast between the two cases. Company B experiences very quick 
response times after making a quotation and hence the confirmation stage for reconsidering DDs and capacity is not important. In contrast, Company $\mathrm{X}$ experiences highly unpredictable delays from the same day to several weeks, with an overall low probability of order confirmation. Thus for Company $\mathrm{X}$, the confirmation stage remains crucial. This difference can be explained by the nature of the businesses. Company B usually deals directly with the end-user of the agricultural conveyor belts and so there is only a need for communication between the two firms before a decision is made. In contrast, Company $\mathrm{X}$ tends to manufacture small components for products that are assembled at a higher point in the supply chain. Therefore, any bids quoted are often then incorporated into a bid being made by a customer to their customer higher up in the chain, and so on. Thus, there is a chain effect that can cause delays in some cases. The effect of this difference is that the strike rate matrix, as described in papers such as Kingsman et al. (1993, 1996) and Kingsman and Mercer (1997) is not relevant in Company $\mathrm{B}$, while it remains an important concept in Company X. It is suggested that this difference is likely to be a general difference between the capital goods and sub-contracting industries.

For the third issue (A3-rush orders), the presence of a limited number of rush orders in Company $\mathrm{B}$ led to a modification to the WLC theory to reserve capacity for this side of the business. This was felt to be particularly important given that, in the capital goods industry, such rush orders can be related to providing replacement parts, which is clearly a strategically important part of the business. It was felt that this required about $10-20 \%$ of the capacity to be reserved, leaving $80-90 \%$ for orders that could be planned. Reserving capacity for these rush orders also required an increase in the planned throughput times for other orders. Thus, this issue is argued to be pertinent to the capital goods industry and not likely to be of relevance to the sub-contractor making smaller components of larger items in a supply chain.

For the fourth issue (A4 - seasonality and volume growth), WLC theory needs to be adapted to accommodate these demand patterns. For the issue of seasonality, the parameterisation of the concept, particularly through the use of workload limits, needs to be flexible rather than rigid. Thus, if the customer/market will accept longer lead times at some periods of the year compared with others, the workload limits can be higher at those times. However, although the theory should be adapted to allow this and enable a smooth transition between alternative limits, it is noted that this response will depend on particular markets. In some instances, it will be important to manage capacity providing higher levels during periods of overload so that lead times can remain the same. This issue of allowing the WLC parameters to be flexible over time is an area that warrants further research.

For volume growth, the WLC concept will suggest higher levels of capacity or longer lead times as time progresses. Obviously, the step increase in capacity is a long-term strategic decision. However, the WLC theory can be adapted to raise a report to indicate capacity usage over time and to track any changes in lead times, thereby providing useful information for this strategic decision.

The final issue (A5-hybrid production) is related to the issue of seasonality and provides an alternative response for the capital goods sector in which there is enough repeat business for stock replenishment orders for spare parts to be released during periods of under-load. This issue is not relevant for Company $\mathrm{X}$ and is perhaps less likely to be relevant to the sub-contracting industry, although it may apply where there is seasonal repeat business. To address this, the WLC theory must be adapted to detect a period of under-load and prompt the user to consider the release of orders at this stage, though the decision to release an order would rest with the user of the system. While this issue has received some attention in other parts of the literature (see, for example, Gorman and Brannon, 2000), the detail of how this should be accomplished in practice with a WLC system is an area for future research. The characteristics of the production setting in Company B suggest that planning the production of MTO products should be integrated with the control of MTS inventory. An inventory sub-system could be used to provide internal orders to the WLC system, which have lower priority than the current external orders. It is currently anticipated that this would be preferable to adapting the WLC system to the extent that it also becomes an inventory control system.

Of the issues raised in this sub-section, the main issue that would benefit from future research beyond the scope of this paper is the issue of allowing the workload limits to change during periods of under-load and over-load. Simulation research could experiment with this change and may 
lead to important insights into its dynamic effects on manufacturing performance measures. Similarly, simulation would provide a good means of investigating alternative methods for detecting a shop under-load and prompting the proposed release of a stock replenishment order.

\subsection{Primary process-related issues (B1-B4)}

The first primary process-related issue (B1assembly requirements) led to the question of how to handle the release of separate parts of an assembly that to undergo separate processing operations before arriving at the assembly point. For Company X, this was addressed by treating the parts as separate orders in the WLC system, but giving them both the same DD. This was considered to be an adequate response, as this should ensure all relevant parts are released in time to reach the assembly point before the DD. For Company B, it was thought to require a more complex release decision, including the revision of the calculation of operation completion dates so as to co-ordinate the release decision of the parts. If one part is released, the system prompts the user to decide whether other related parts should also be released. While authors such as van de Wakker (1993) and Silva et al. (2006) have begun to explore the role of incorporating links between sub-assemblies and "child" components in the design of WLC systems, further research is needed to assess whether the increase in complexity this introduces is justified by improved DD performance.

The second issue in this section (B2-sequencedependent set-up times) was identified in the context of Company B for only a limited number of machines; this is an issue that has received relatively little attention in the WLC literature (see, for example, Missbauer, 1997). It was decided that longer planned throughput times should be used at these machines at the customer enquiry stage. If this is a key issue for a company, then it is concluded that the WLC methodology applied to Company B would not be an appropriate approach for planning and scheduling the workload. However, it is noted that well-known current manufacturing theory aims to reduce set-up times wherever possible so that they do not have a significant impact on throughput times. It is also noted that it may be possible to consider the use of other forms of WLC to accommodate this issue, such as that discussed by Missbauer (1997).
For Company $\mathrm{X}$, this issue of sequence-dependent set-up times only arose if lot splitting had taken place at the job release stage; the issue of lot splitting has also received relatively little attention in the WLC literature (see, for example, Missbauer, 2002). The solution for Company $X$ was to not assume constant throughput times as the approach nears the more detailed planning levels. Such an assumption is acceptable at the rough-cut customer enquiry stage, but not at the point of job release when it is important to ensure that the quoted DDs are met wherever possible. Instead, from the job entry stage onwards, operation completion dates were proposed based on actual capacity availability.

In relation to the third issue (B3-alternative shop floor routings), machines were grouped for both companies so that the alternative routings only existed within the machine groupings. This enables the shop floor workers to make the final decision on which machines are used for each order, delaying detailed planning decisions until after jobs have been released, and enabling the full flexibility of the machines to be exercised. This approach is appropriate even when the interchange ability is not symmetric (i.e., when machines are semi-interchangeable), as is the case for Company $\mathrm{B}$, as the shop floor workers can look ahead given the improved visibility that results from the reduced number of orders present on the shop floor.

The fourth issue (B4 - industry-specific processes, such as the oven process for Company B that causes lead time delays due to batching) requires further research. In both companies, this has not been addressed through any attempt to adapt the WLC theory, although in both cases, it is felt that a response to this issue will be needed in the long run.

In conclusion, while WLC theory can deal with some aspects of the primary manufacturing process, not all issues have been fully investigated and so further research is needed to develop the theory of the WLC concept further. By conducting further case study research, it is anticipated that further primary manufacturing process-related issues may emerge. For some issues, such as the presence of dominant sequence-dependent set-up times, it is argued that this can make the use of some variants of WLC inappropriate.

\subsection{WLC system-related issues (C1-C3)}

The first issue here ( $\mathrm{C} 1-$ WLC-related start-up issues) is primarily related to a key aim of WLC: to 
reduce, and gain control of, lead times. Given this aim, it is likely that the issue of initial long lead times in Company $\mathrm{X}$ will be common across many potential users of WLC, particularly those firms operating as a job shop (given their continued need for high levels of product customisation and flexibility). The solution proposed is the gradual reduction of workload limits thus aiming to gain control of lead times once implementation is complete, rather than starting with limits that will lead to the advised rejection of all incoming orders until the backlog is cleared.

For Company $\mathrm{B}$, the initial start-up issues relate more to the variation in throughput times across operations. Two alternative approaches to this issue have been considered. Firstly, planned times in WLC could be allowed to vary according to these differences. Secondly, WLC could be used to reduce the longer throughput times and hence gain more control of the lead times as in Company X. In many cases, both approaches may be needed, with the first being the initial response followed by the second as the longer term aim where this is considered feasible. Where altering the workload limits over time is the chosen approach, further research is needed to identify how this can best be achieved, as discussed under issue A4 above. Parameter setting, such as during the initial implementation and WLC start-up phase, remains an ongoing research issue; the most significant contributions to date include those by Perona and Portioli (1998) and Land (2004).

The second issue (C2 - incomplete routing data before process planning have taken place) led to a particularly significant change to WLC theory. In many simulation experiments, it is assumed that job routing data are available at the customer enquiry stage. However, this was not the case in either company, as also highlighted by van de Wakker (1993). For Company B, it was possible to determine which work centres will be involved, but detailed times are not estimated until an order has been confirmed. Similarly, in Company X, it is not considered worthwhile by management to produce such data when bidding for jobs given that there is a high probability of the order not being confirmed. Thus, while it is realistic for this company to have data for repeat orders, it is not considered worthwhile to develop these data for enquiries for products that have not been manufactured before. Thus, instead of the WLC theory assuming that detailed job routing data would be available, the customer enquiry stage has been adapted to include an option to only require an indication of the work centres a job will visit. Work centre throughput norms are then used to estimate the overall time required for the job. Users of the WLC methodology can then seek to regulate these work centre throughput norms over time to stabilise and reduce lead times (as discussed above in $\mathrm{C} 1$ ).

The third issue (C3 - time-span-dependent critical resources) is related to the manner in which the WLC concept deals with bottlenecks. It is noted that different variants of WLC differ in their consideration of this issue. For the concept used in Company $\mathrm{X}$, it is assumed that bottlenecks do not exist or are not significant and this assumption is appropriate for the shop characteristics of this case study. Other approaches to WLC do assume that there are bottlenecks as is the case in Company B (see, for example, Enns and Prongue Costa, 2002). Despite attempts to accommodate the "wandering bottleneck problem" in other branches of the planning and control literature (see, for example, Simons and Simpson, 1997), as yet no approaches have been developed to accommodate the differences between long-term and short-term potential bottlenecks in the context of WLC. Therefore, the issue identified here requires further research.

In conclusion, all of these issues relate to the development of the theory that underpins the WLC concept. While further theoretical development of WLC is needed for one of the issues, solutions have been found for the others. These proposed solutions would benefit from further research via simulation studies.

\subsection{Organisational embedding-related issues (D1-D3)}

The first issue regarding organisational embedding (D1-awareness of the concept of WLC) proved a particularly difficult aspect of the implementation process. It is felt to be of particular significance to WLC, given that it currently tends to be an unknown concept at the point of introduction, unlike concepts such as ERP or Lean Production. This was the case for both Company $\mathrm{X}$ and Company B. Clearly, having agreed to participate in the introduction of a WLC system, both organisations had bought into the aims and objectives of the approach at the outset and had the necessary support of senior management. Nonetheless the issue of training was key and it is 
concluded that it is important to ensure that all WLC system users have enough of an understanding of the concept to make appropriate use of the system without requiring all of the details to be regularly explained by the IT support system. For example, in Company $\mathrm{B}$, ongoing training and support is being provided, using tools such as throughput, and order progress, diagrams (see, for example, Wiendahl, 1995; Soepenberg et al., 2006).

In addition, as the implementation progressed in Company $\mathrm{X}$, it was regularly necessary to remind the company of the detail of the concept. For example, particular effort was required to persuade employees against the inclusion of a detailed scheduling module at the initial implementation stage. It was felt that this request arose largely from a misunderstanding of the aims and functionality of WLC. Other requests from the users were met as far as possible, as is required to gain acceptance, promote "ownership" and embed the system in the organisational culture (see, for example, Johnson and Scholes, 1993). For example, Company $\mathrm{X}$ requested minimal data input, which was accommodated. They also requested the ability to change operation completion dates, this was also permitted but the aggregate planned and total workload calculations were not affected. Thus, this change in the concept to meet company needs would not have an affect on the control of lead times anticipated by the use of WLC.

The second issue (D2-user visibility) is linked to the previous issue of training. In Company $\mathrm{X}$, training users meant that it was concluded that all detail did not need to be included in the system. For example, final decisions regarding capacity are made by the user: advice on the capacity levels required is given by the system but detailed calculations are not shown. Similarly, the system developed for Company B provided support for capacity decisions without showing the underlying calculations. For example, to support possible capacity adjustment, the system will simply identify the capacity group that constrains the shortest possible delivery time without justification of the information presented. In both case studies, extensive use of graphs within the software tools also facilitates the user understanding: for Company B, this included the use of graphs to show the logic of calculations but not the calculations themselves.

Both of the above issues stress the need for appropriate training. Further research is needed to develop an on-line training tool for the approach.
This would also facilitate the development of online help, available to the user as and when required.

The third issue (D3 - support of task structures) is an important issue for ensuring there is a good fit between the business processes of the company and the information requirements of the WLC system. This issue is typically explored in the context of integration between sales/marketing and the production/engineering departments (see, for example, Kingsman et al., 1993, 1996; De Souza, 1995). In the case of Company B, planning and sales tasks were separate within the current task structure meaning that, in order to meet the needs of the WLC system, cross-functional co-ordination was required during the management of every customer enquiry. For Company $\mathrm{X}$, the company size meant that sales and production planning tasks were often undertaken by the same member of staff making this less of an important issue to consider. This remains an important issue for future research to consider in the specific context of WLC. While previous research has advocated the need for co-ordination between production/engineering and sales/marketing, little has been written on the level, frequency and nature of this co-ordination.

In summary, embedding the use of the WLC concept in the organisation is largely a matter of appropriate training and the development of further tools to assist this learning process is needed. In addition, there is a need to consider which decisionmaking bodies will make use of the WLC output and what levels of cross-functional co-ordination are needed to make effective use of the concept. All of these issues relate to the development of implementation strategy for WLC.

\subsection{Information flow-related issues (E1-E2)}

The first issue regarding information flow (E1system -related start-up issues) has illustrated the need to run the WLC system initially without using the control structures in order to fill the database. For Company B, this entailed running the system for at least a month given the nature of the current ERP system already in use in the company, which supplies the data. For Company X, a stand-alone system has been partially implemented. A month of elapsed time was not required, but jobs needed to be put through the system and released manually to create the initial start-up conditions with the correct jobs released to the shop floor. Therefore, the issue of start-up for the initial database can be argued to 
be company specific and it is unlikely that a generic solution will be available.

The broader issue of IT-integration in SMEs is not specific to WLC, but is an issue for all types of IT systems that need to be integrated. It has been argued by authors such as Jordan and Michel (2000) that this is typically an extremely problematic issue for many of the software solutions that need to be integrated within manufacturing firms and remains a challenge for the next generation of manufacturers.

The final issue to be considered (E2 - determining feedback processes from, and data provision to, the ERP system) is also linked to the issue of integration. This issue only arose in Company $\mathrm{B}$, and here the ERP system is likely to be replaced in the near future. However, this change will only alter the nature of the issue rather than remove the need to research it. Therefore, the new implementation issues that arose in relation to information flow are mostly of a technical nature, which would benefit from further research in collaboration with computer science specialists.

\section{Conclusion and future research issues}

The process of implementation is an important issue; however, within the context of WLC, it has received inadequate attention in the literature to date. It is therefore important to build up a body of WLC-oriented case study evidence to develop an associated implementation strategy and to ensure that the theory underpinning WLC systems can be realistically applied to relevant industrial contexts. This paper has contributed to filling this gap by considering a capital goods manufacturer and a small sub-contracting company, considered to be typical of two main types of industrial contexts for which WLC has been designed. Through a process of inductive research, a set of implementation issues has been developed, which are argued to be of relevance to future attempts to implement WLC. Thus, the paper aims to facilitate the more widespread implementation of WLC in practice. Future research is needed to further develop the theory discussed here in the context of other case study companies. Many of the issues identified may also be of relevance to the implementation of other innovative PPC methods: further case study research would be needed to verify this.

Two main research questions were identified at the outset of this research, as presented in Section 3.
The first asked: "what are the implementation issues that arise in the context of WLC'? This paper has focused on issues that have not yet received adequate attention in the literature. The issues identified using this case study research have been summarised in Tables 2-6, where a total of 17 issues have been categorised into: 5 customer/marketrelated issues; 4 primary process issues; 3 WLC system issues; 3 issues of organisational embedding; and 2 issues related to information flow.

The second research question given in Section 3 above asked: "how should the implementation issues that arise in the context of WLC be addressed to enable improved implementation in practice"? Once the issues had been identified, specific and more detailed research questions emerged for each of the 17 issues. Table 7 summarises these more detailed emerging research questions and the response that was adopted for each of the case study companies. In some cases, the response was different for each case study, while for others the same response was adopted. The latter is indicated in Table 7 by merging the two right-hand side columns where appropriate. This table also indicates whether the response contributes to a change in WLC theory or whether it contributes to the development of an element of implementation strategy for WLC.

For some of the implementation issues raised, specific issues that require further investigation have been identified in the detailed discussion of the case study evidence presented in this paper. Hence, while providing a rare insight into the process of implementing WLC systems in practice and providing guidance on how to address implementation issues of particular importance to WLC, the paper also has implications for the direction of future research in the field of WLC. These issues are summarised below-the implementation issue to which they relate is indicated in brackets at the end of each point, using the same numbering system as used in Tables 2-7 above. Many of the issues would benefit from theoretical research, such as through the use of simulation studies:

- Allowing the WLC parameters to be flexible over time to accommodate issues of seasonality requires further theoretical and simulation research to identify how a smooth transition can be made from one WLC limit to another. This also affects the introduction of WLC when lead times are initially very long and WLC is being used to 
Table 7

Summary of emerging WLC research questions and appropriate responses

Emerging research questions
Appropriate responses

Company B (capital goods)

Use specific due dates in the WLC system to track progress (implementation strategy)

A1: How can unrealistic and unspecified due dates be handled throughout the order process?

A2: How can uncertainty at the customer enquiry stage be most effectively incorporated in the design of the WLC concept?

A3: How can future, replacement part, rush orders be considered most effectively within the WLC concept?

A4: How should demand patterns be adopted in e.g., parameterisation of the WLC concept?

A5: How can the release of stock replenishment orders in periods of under-load be fully accommodated?

B1: How should the workload requirements of two separate parts be treated when making a release decision based on workload norms?

B2: How can set-up sequences be incorporated in WLC decisions, which normally assume constant throughput times per operation?

B3: How can the grouping of machines be organised such that the full flexibility potential of capacities is utilised?

B4: How can the basic WLC approach of creating regular order arrival processes at machines be adapted for conflicting batching requirements?

C1: How can the transition between the actual situation and the situation as ultimately enabled by WLC be realised? To what extent does the control imposed by WLC enable the use of standardised throughput times across operations?

$\mathrm{C} 2$ : How can acceptance and due date assignment decisions best be taken when there is incomplete routing data?

C3: In what way can appropriate capacity groups be defined to reflect the critical or bottleneck resources at different decision levels?

D1: How can planners and other personnel be trained such that decisions will be taken in correspondence with the integrated WLC approach?

D2: How can a good balance be realised between showing (e.g., graphically) only results of WLC calculations, while maintaining sufficient understanding of the underlying logic for planners to take the right measures?

D3: Which task structures can be supported and and/or simplified by the WLC concept and which requirements are imposed by the concept?

Uncertainty at the customer enquiry stage is unlikely to be a significant issue in the capital goods sector (WLC theory)

Reserve $10-20 \%$ of capacity for rush orders (implementation strategy)

Allow WLC parameters to vary over time (WLC theory)

Adapt WLC to identify periods of underload and prompt the user to release stock replenishment orders (WLC theory)

Aim to co-ordinate the release of the parts (WLC theory)

Use longer planned throughput times at these machines at the customer enquiry stage (WLC theory). strategy)

Requires further research (WLC theory)

Either allow throughput times to vary across operations or enable the gradual reduction of workload limits at machines with initially long throughput times (WLC theory)

Requires further research (WLC theory)
Increase co-ordination between the marketing and production functions, as this is imposed by the concept (implementation strategy)

Company X (subcontractor)

Gradual change to the use of realistic due dates (implementation strategy)

Strike rate matrix likely to be of use only in the subcontracting sector ( $W L C$ theory)

N/A - unlikely to be an issue for subcontractors

Adapt WLC to provide information on step changes in demand (WLC theory)

$\mathrm{N} / \mathrm{A}$ - unlikely to be an issue for subcontractors.

Give the parts the same due date and then deal with them individually ( $W L C$ theory)

From job entry onwards, base decisions on actual capacity available (WLC theory)

Group machines so that alternative routings only exist in the group (implementation

Gradual reduction of workload limits to gain control of lead times (WLC theory)

Use throughput norms at the customer enquiry stage so that only an indication of the required machines is needed in order to calculate delivery lead times (WLC theory)

N/A

Ongoing training and support using tools such as throughput and order progress diagrams. Develop an on-line training tool (implementation strategy)

Provide graphs and advice for decisions without giving calculations. Provide an on-line help system as an option for users that need more explanation (implementation strategy)

Good co-ordination already existed, but retaining this may become an issue if the company becomes larger (implementation strategy) 
Table 7 (continued)

\begin{tabular}{lll}
\hline Emerging research questions & Appropriate responses & Company X (subcontractor) \\
\cline { 2 - 3 } & Company B (capital goods) & Manual/clumsy integration essential. \\
\hline $\begin{array}{l}\text { E1: How can the different levels of IT-integration } \\
\text { in SMEs be supported in WLC? In which ways can } \\
\text { the start-up database for a WLC system best be } \\
\text { filled? }\end{array}$ & $\begin{array}{l}\text { Integration with existing IT clumsy. Start-up } \\
\text { by running the WLC system for at least a } \\
\text { month without the use of WLC decision- } \\
\text { making facilities (implementation strategy) }\end{array}$ & $\begin{array}{l}\text { Start-up by releasing jobs manually to } \\
\text { populate the database and create the } \\
\text { initial shop floor workload } \\
\text { (implementation strategy) }\end{array}$ \\
$\begin{array}{l}\text { E2: How can WLC planning systems be integrated } \\
\text { with the ERP-systems of the company? }\end{array}$ & Requires further research in collaboration with computer scientists (WLC theory)
\end{tabular}

gain control of lead times and gradually reduce them (A4, C1, C2).

- Similarly, simulation would provide a good means of investigating alternative methods for detecting a shop under-load and prompting the proposed release of a stock replenishment order (A5).

- Simulation could also be used to assess whether it is important to release all parts of a sub-assembly at the same time, or whether it is sufficient to give all parts the same DD in the anticipation that this would allow them to arrive at the assembly point in time for completion prior to the DD (B1).

- Theoretical development of the WLC approach is needed to allow for batching problems that arise as a result of industry-specific processes, such as the oven process in Company B (B4).

- Further development of WLC theory is needed to accommodate the differences between long- and short-term potential bottlenecks in cases where bottlenecks cannot be eliminated (C3).

- Development of an on-line training tool for the WLC approach is proposed as a means of facilitating understanding and appropriate use of the WLC system (D1, D2).

- The integration of WLC with other software systems already in place in an organisation, including ERP systems, is an essential challenge to overcome. This is a broad issue affecting many software solutions which manufacturing companies seek to integrate (E1, E2).

Through the insights presented in this paper, and the further research identified above, it is argued that more widespread implementation of WLC will be possible. This in turn will facilitate more detailed collection of empirical evidence of the effect of WLC on performance in practice.

\section{References}

Amaro, G.M., Hendry, L.C., Kingsman, B.G., 1999. Competitive advantage, customisation and a new taxonomy for non maketo-stock companies. International Journal of Operations \& Production Management 19 (4), 349-371.

Bechte, W., 1988. Theory and practice of load oriented manufacturing control. International Journal of Production Research 26 (3), 375-395.

Bechte, W., 1994. Load oriented manufacturing control just in time production for job shops. Production Planning \& Control 5, 292-307.

Benbasat, I., Goldstein, D.K., Mead, M., 1987. The case research strategy in studies of information systems. MIS Quarterly 11 (3), 369-386.

Bergamaschi, D., Cigolini, R., Perona, M., Portioli, A., 1997. Order review and release strategies in a job shop environment: A review and a classification. International Journal of Production Research 35 (2), 399-420.

Bertrand, J.W.M., Van Ooijen, H.P.G., 2002. Workload based order release and productivity: A missing link. Production Planning \& Control 13 (7), 665-678.

Bertrand, J.W.M., Wortmann, J.C., 1981. Production Control and Information Systems for Component-Manufacturing Shops. Elsevier, Amsterdam.

De Souza, A.A., 1995. Developing a knowledge based decision support system to aid make-to-order companies in cost estimation and pricing decisions. Ph.D. Thesis, Lancaster University, Lancaster, UK.

Dowlatshahi, S., 2005. Strategic success factors in enterprise resourceplanning design and implementation: A case-study approach. International Journal of Production Research 43 (18), 3745-3771.

Eisenhardt, K.M., 1989. Building theory from case study research. Academy of Management Review 14 (4), 532-550.

Eisenhardt, K.M., 1991. Better stories and better constructs: The case for rigor and comparative logic. Academy of Management Review 16 (3), 620-627.

Enns, S.T., Prongue Costa, M., 2002. The effectiveness of input control based on aggregate versus bottleneck workloads. Production Planning \& Control 13 (7), 614-624.

Fry, T.D., Smith, A.E., 1987. A procedure for implementing input/output control: A case study. Production and Inventory Management Journal 28 (4), 50-52.

Gelders, L.F., Van Wassenhove, L.N., 1981. Production planning: A review. European Journal of Operational Research 7 (2), 101-110. 
Gorman, M.F., Brannon, J.I., 2000. Seasonality and the production-smoothing model. International Journal of Production Economics 65, 173-178.

Handfield, R.B., Melnyk, S.A., 1998. The scientific theorybuilding process: A primer using the case of TQM. Journal of Operations Management 16, 321-339.

Hendry, L.C., 1989. A decision support system to manage delivery and manufacturing lead times in make to order companies. Ph.D. Thesis, Lancaster University, Lancaster, UK.

Hendry, L.C., 2005. Product customisation: An empirical study of competitive advantage and repeat business. Lancaster University Management School Working Paper Series.

Hendry, L.C., 2006. Workload control: For effective integration of SME's in the supply chain. In: Proceedings of the International Workshop on Successful Strategies in Supply Chain Management, Hong Kong, 2006, pp. 17-23.

Hendry, L.C., Kingsman, B.G., 1989. Production planning systems and their applicability to make to order companies. European Journal of Operational Research 40, 1-15.

Hendry, L.C., Elings, P., Pegg, D., 1993. Production planning for an artists studio-A case study. European Journal of Operational Research 64, 12-20.

Henrich, P., 2005. Applicability aspects of workload control in job shop production. Ph.D. Thesis, University of Groningen, The Netherlands, Labyrint Publications, Ridderkerk, The Netherlands, ISBN:9053350470.

Henrich, P., Land, M.J., Gaalman, G., Van Der Zee, D.J., 2004. Reducing feedback requirements of workload control. International Journal of Production Research 42 (24), 5235-5252.

Henrich, P., Land, M.J., Gaalman, G., 2006. Grouping machines for effective workload control. International Journal of Production Economics 104, 125-142.

Hong, K.K., Kim, Y.G., 2002. The critical success factors for ERP implementation: An organisational fit perspective. Information \& Management 40, 25-40.

Hopp, W.J., Spearman, M.L., 1996. Factory Physics: Foundation of Manufacturing Management. Irwin, USA.

Johnson, G., Scholes, K., 1993. Exploring Corporate Strategy: Text and Cases, third ed. Prentice-Hall, New York.

Jordan Jr., J.A., Michel, F.J., 2000. Next Generation Manufacturing: Methods and Techniques. Wiley, New York.

Kingsman, B.G., Mercer, A., 1997. Strike rate matrices for integrating marketing and production during the tendering process in make-to-order subcontractors. International Journal of Operational Research 4 (1), 251-257.

Kingsman, B.G., Worden, L., Hendry, L.C., Mercer, A., Wilson, E., 1993. Integrating marketing and production planning in make-to-order companies. International Journal of Production Economics 30-31, 53-66.

Kingsman, B.G., Hendry, L.C., Mercer, A., De Souza, A., 1996. Responding to customer enquiries in make-to-order companies: Problems and solutions. International Journal of Production Economics 46-47, 219-231.

Land, M.J., 2004. Workload control in job shops: Grasping the tap. Ph.D. Thesis, University of Groningen, The Netherlands. Labyrint Publications, Ridderkerk, The Netherlands, ISBN:9053350276.

Land, M.J., Gaalman, G., 1996. Workload control concepts in job shops-A critical assessment. International Journal of Production Economics 46-47, 535-548.
Mandal, P., Gunasekaran, A., 2003. Issues in implementing ERP: A case study. European Journal of Operational Research 146, 274-283.

Meredith, J., 1998. Building operations management theory through case and field research. Journal of Operations Management 16, 441-454.

Mintzberg, H., 1988. Generic strategies: Toward a comprehensive framework. In: Lamb, R., Shrivastava, P. (Eds.), Advances in Strategic Management, fifth ed. Jai Press Inc., Greenwich, CT, pp. 1-67.

Missbauer, H., 1997. Order release and sequence-dependent setup times. International Journal of Production Economics 49, 131-143.

Missbauer, H., 2002. Lot sizing in workload control systems. Production Planning \& Control 13 (7), 649-664.

Motwani, J., Mirchendani, D., Madan, M., Gunasekaran, A., 2002. Successful implementation of ERP projects: Evidence from two case studies. International Journal of Production Economics 75, 83-96.

Muscatello, J.R., Small, M.H., Chen, I.J., 2003. Implementing Enterprise Resource Planning (ERP) systems in small and midsize manufacturing firms. International Journal of Operations \& Production Management 23 (8), 850-871.

Oosterman, B., Land, M.L., Gaalman, G., 2000. The influence of shop characteristics on workload control. International Journal of Production Economics 68 (1), 107-119.

Park, C., Song, J., Kim, J.-G., Kim, I., 1999. Delivery date decision support system for the large scale make-to-order manufacturing companies: A Korean electric motor company case. Production Planning \& Control 10 (6), 585-597.

Perona, M., Miragliotta, G., 2000. Workload control: A comparison of theoretical and practical issues through a survey in field. In: Eleventh International Working Seminar on Production Economics, Igls, Innsbruck, Conference Proceedings, pp. 1-14.

Perona, M., Portioli, A., 1998. The impact of parameters setting in load oriented manufacturing control. International Journal of Production Economics 55, 133-142.

Petroni, A., 2002. Critical factors of MRP implementation in small and medium sized firms. International Journal of Operations \& Production Management 22 (3), 329-348.

Sabuncuoglu, I., Karapinar, H.Y., 1999. Analysis of order review/release problems in production systems. International Journal of Production Economics 62, 259-279.

Silva, C., Roque, L., Almeida, A., 2006. MAPP-A web-based decision support system for the mould industry. Decision Support Systems 42 (2), 999-1014.

Simons, J.V., Simpson III, W.P., 1997. An exposition of multiple constraint scheduling as implemented in the goal system (formerly disaster). Production and Operations Management 6 (1), 3-22.

Soepenberg, G.D., Land, M.J., Gaalman, G.J.C., 2006. The order progress diagram: A supportive tool for diagnosing dependability in make-to-order companies, In: Fourteenth International Working Seminar on Production Economics, Innsbruck, Austria, vol. 3, pp. 315-325, pre-prints.

Stadtler, H., Kilger, C. (Eds.), 2002. Supply Chain Management and Advanced Planning: Concepts, Models, Software and Case Studies. Springer, Berlin.

Stevenson, M., 2006a. Refining a workload control (WLC) concept: A case study. International Journal of Production Research 44 (4), 767-790. 
Stevenson, M., 2006b. Bridging the gap: Refining a workload control concept for practical implementation. Ph.D. Thesis, Lancaster University, Lancaster, UK.

Stevenson, M., Hendry, L.C., 2006. Aggregate load oriented workload control: A review and a reclassification of a key approach. International Journal of Production Economics 104, 676-693.

Stevenson, M., Hendry, L.C., Kingsman, B.G., 2005. A review of production planning and control: The applicability of key concepts to the make to order industry. International Journal of Production Research 43 (5), 869-898.

Stuart, I., McCutcheon, D., Handfield, R., McLachlin, R., Samson, D., 2002. Effective case research in operations management: A process perspective. Journal of Operations Management 20, 419-433.

Sumner, M., 2000. Risk factors in enterprise-wide/ERP projects. Journal of Information Technology 15, 317-327.

Suri, R., 1999. Quick Response Manufacturing: A Company Wide Approach to Reducing Lead Times. Productivity Press, Inc.

Tobin, N.R., Mercer, A., Kingsman, B., 1988. A study of small subcontract and make to order firms in relation to quotation for orders. International Journal of Operations \& Production Management 8 (6), 46-59.
Van de Wakker, A.M., 1993. Throughput time control and due date reliability in tool and die shops. Ph.D. Thesis, University of Eindhoven, The Netherlands.

Vollmann, T.E., Berry, W.L., Whybark, D.C., Jacobs, F.R., 2004. Manufacturing Planning and Control for Supply Chain Management, fifth ed. McGraw-Hill/Irwin, New York.

Voss, C., Tsikriktsis, N., Frohlich, M., 2002. Case research in operations management. International Journal of Operations \& Production Management 22 (2), 195-219.

Wiendahl, H.P., 1995. Load Oriented Manufacturing Control. Springer, Berlin, Heidelberg, New York.

Wiendahl, H.P., Scholtissek, P., Fastabend, H., 1995. Simulationbased training systems for job shop control (TRAIN-F). In: Riis, J.O. (Ed.), Simulation Games and Learning in Production Management. Chapman \& Hall, London.

Yin, R.K., 2003. Case Study Research: Design and Methods, third ed. Sage, London.

Yusuf, Y., Gunasekaran, A., Abthorpe, M.S., 2004. Enterprise information systems project implementation: A case study of ERP in Rolls-Royc. International Journal of Production Economics 87, 251-266.

Zäpfel, G., Missbauer, H., 1993. New concepts for production planning and control. European Journal of Operational Research 67, 297-320. 